\title{
Artificial salmon tracking algorithm: Preliminary designing approach for optimizing the integrated mixed energy composition
}

\author{
A.N. Afandi ${ }^{1,2, *}$, Irham Fadlika ${ }^{1}$, Quota Alief $\operatorname{Sias}^{1}, Y$. Rahmawati ${ }^{1}$, D. Lestari ${ }^{1}$, A.N. \\ Handayani $^{1}$, Yunis Sulistyorini ${ }^{3}$, Farrel C.W.A. ${ }^{2}$, and Michiko R.S.A. ${ }^{2}$ \\ ${ }^{1}$ Electrical Engineering Department, Universitas Negeri Malang, 65145 Malang, Indonesia \\ ${ }^{2}$ Smart Power and Advanced Energy Systems Center, 65312 Batu, Indonesia \\ ${ }^{3}$ Department of Mathematics, IKIP Budi Utomo, 65119 Malang, Indonesia
}

\begin{abstract}
Recently, an energy mix providing becomes an important problem to face unsustainable energy sources fuelled by coal derivation. The optimal composition between various energy sources also leads to the generated portion of the unit commitment. By considering this issues, these works are subjected to find out the optimal scheduled production of the energy mix throughout an optimization problem considered conventional and renewable energy sources. Moreover, these studies also introduce Artificial Salmon Tracking Algorithm for carrying out the problem. By considering technical requirements, results show that the total energy mixing is produced dynamically to feed the hourly demand. The contribution of the conventional and renewable energy sources affect to discharged pollutants.
\end{abstract}

\section{Introduction}

Nowadays, energy consumption becomes one of the parameters to measure industrial operations and daily activities. This energy usage also leads to power productions from various energy producers. Technically, the most popular usable energy is electricity with numerous type consumers [1]. The energy producers are fuelled commonly using coal, water, and gas system structures for producing regularly in the power unit commitment. Operationally, the power is produced gradually within 24 hours using a joined power sharing of the energy producer from many types of generating units. Generating units are designed based on the maximum and minimum power limits while contributing on the operating system [2]-[4]. In addition, the power participation of each generating unit is dispached using a power quota portion (PQP) of existed possibilities where energy users are located far away from the potential supplier [5]-[8]. To cover the PQP, energy producers should be designed in suitable composition for the all operating plant period of interconnected structures. This interconnection is associated with scheduled power outputs for the PQP and corresponded to a dynamic problem of load demand changes for 24 hours [9]-[12].

\footnotetext{
* Corresponding author: an.afandi@um.ac.id
} 
Since the energy fossil fuel source crisis has been become major issues and the public awareness of the environmental protection also has been increased, the system processes have to modify operational strategies to cover these problems. Natural explorations are needed to find out the potential resource in nature to replace energy fossil sources subjected to an integrated renewable energy source (IRES) such as wind energy source (WES) and solar energy source (SES) [13]-[15]. By considering an environmental friendly aspect, the pollutant emission quota (PEQ) also becomes a dynamic problem to meet hourly load demands. To cover both problems, single quota function (SQF) is used to combine PQP and PEQ problems which are determined together at the same time as an optimization problem. Focus on the optimization problem, many methods can be used to carry out optimization problems whereas the proposed approach covers mathematical programmings and optimization techniques [16], [17]. Recently, intelligent techniques have occupied an important position in the computation for breaking out various problems contrasted with traditional approaches [8], [18]. This paper covers the solution of the SQF using artificial salmon tracking algorithm (ASTA) as a novel computational intelligence. Furthermore, technical limitations and environmental requirements are also applied to the conventional and hybrid energy systems based on the hourly suitable solutions.

\section{Integrated Mixed Energy Composition}

Dynamically, the SQF considers the hourly demand and energy production. This problem also meets possible combinations of the conventional energy sources (CES) [19], [20]. By considering an environmental requirement, a penalty factor is used to combine emission and cost fuctions of the power plants [3], [11], [21]. In these studies, a new penalty technique is also applied to the PEQ and the PQP. This technique is given in a dynamic penalty factor (DPF) approach associated with the allowed emission discharge (AED), the total produced emission (TPE), and the over rate emission coefficient (OREC) as given in Equations (1) to Equation (3).

In particular, the IRES is integrated into the energy system operation (ESO) which is developed using the CES and the SES. The ESO produces power outputs to meet the total load demand which is operated within 24 hours. Technically, a high reliable electricity provider is very important to cover the optimal energy dispatching and to meet a demand growth [2], [7], [12]. In general, the SQF is executed by considering several constraints in terms of the power balance, power load flows with embedding losses for the lines, capacity limits of powers, fluctuated voltage, power transfer capability limits, ramp limits, and the emission standard. The ESO covers the CES, WES, and SES.

By considering the period time operation and these conditions, the scheduled power outputs are planned for 24 hours based on load demand changes by the present hour to the next hour as given in Equation (4) to Equation (6).

$$
\begin{aligned}
& \operatorname{OREC}_{\mathrm{z}}=\frac{\sum \mathrm{TPE}_{\mathrm{zs}}-\sum \mathrm{TAE}_{\mathrm{zs}}}{\mathrm{nG}_{\mathrm{z} \cdot \Sigma \mathrm{TPE}_{\mathrm{zs}}}} \\
& \mathrm{h}_{\mathrm{z}}=\left\{\mathrm{hG}_{\mathrm{zs}}\right\} \\
& \mathrm{dh}_{\mathrm{z}}=\mathrm{OREC}_{\mathrm{z}} \cdot \mathrm{rh}_{\mathrm{z}}, \\
& \sum_{\mathrm{i}=1}^{\mathrm{ng}} \mathrm{PP}_{\mathrm{i}}^{\mathrm{t}}=\sum_{\mathrm{i}=1}^{\mathrm{ng}} \mathrm{PCES}_{\mathrm{i}}^{\mathrm{t}}+\sum_{\mathrm{i}=1}^{\mathrm{ng}} \mathrm{PWES}_{\mathrm{i}}^{\mathrm{t}}+\sum_{\mathrm{i}=1}^{\mathrm{ng}} \mathrm{PSES}_{\mathrm{i}}^{\mathrm{t}}, \\
& \sum_{\mathrm{i}=1}^{\mathrm{ng}} \mathrm{PP}_{\mathrm{i}}^{\mathrm{t}}=\mathrm{TD}_{\mathrm{i}}^{\mathrm{t}}+\mathrm{TLOSS}_{\mathrm{i}}^{\mathrm{t}}, \\
& \sum_{\mathrm{i}=1}^{\mathrm{ng}} \mathrm{EP}_{\mathrm{i}}^{\mathrm{t}}=\sum_{\mathrm{i}=1}^{\mathrm{ng}} \mathrm{PP}_{\mathrm{i}}^{\mathrm{t}} \mathrm{x} \Delta \mathrm{T}_{\mathrm{i}}^{\mathrm{t}},
\end{aligned}
$$

where $\mathrm{OREC}_{\mathrm{z}}$ is the over rate emission coefficient of the $z^{\text {th }}$ iteration, TPE $\mathrm{zs}$ is the total produced emission of the $\mathrm{s}^{\text {th }}$ generating unit of the $\mathrm{z}^{\text {th }}$ iteration $(\mathrm{kg} / \mathrm{h}), \mathrm{TAE}_{\mathrm{zs}}$ is the total 
allowed emission of the $\mathrm{s}^{\text {th }}$ generating unit of the $\mathrm{z}^{\text {th }}$ iteration $(\mathrm{kg} / \mathrm{h}), \mathrm{nG}_{\mathrm{z}}$ is the number of generating units of the $\mathrm{z}^{\text {th }}$ iteration exceeded the allowed emission, $\mathrm{h}_{\mathrm{z}}$ is a penalty factor set of the $\mathrm{z}^{\text {th }}$ iteration $(\$ / \mathrm{kg}), \mathrm{hG}_{\mathrm{zs}}$ is the individual penalty factor of the $\mathrm{s}^{\text {th }}$ generating unit exceeded the allowed emission of the $\mathrm{z}^{\text {th }}$ iteration step $(\$ / \mathrm{kg}), \mathrm{dh}_{\mathrm{z}}$ is the dominant penalty factor of the $\mathrm{z}^{\text {th }}$ iteration $(\$ / \mathrm{kg})$, and $\mathrm{rh}_{\mathrm{z}}$ is the selected $\mathrm{hG}_{\mathrm{zs}}$ of the $\mathrm{z}^{\text {th }}$ iteration for the highest $\mathrm{TPE}_{\mathrm{zs}}, \mathrm{t}$ is period intervals of time $(\mathrm{t}=1,2,3, \ldots, \mathrm{e})$, e is the total period, ng is the iterating number, PP is a power production, PCES is a power production of the CES, PWES is the power production of the WES, PSES is the power production of the SES, TD is the total demand, TLoss is the total loss, EP is the energy production, and $\Delta \mathrm{T}$ is a duration of present and past hours.

\section{Optimizing Procedures}

As mentioned before, ASTA is also explored in these studies. This algorithm is inspired by a migration of Salmon fish. In general, a salmon life history can be illustrated using a natural behavior in terms of spawning fish and returning from the ocean. In addition, Figure 1 shows the life time of salmon cycles. Habitually, the salmon run is the moving time migrated from the ocean, swim to the upper reaches of rivers where spawning on gravel beds [22]. Early life of salmon spends in rivers continue to swim out to sea for the living adult [22]-[25].

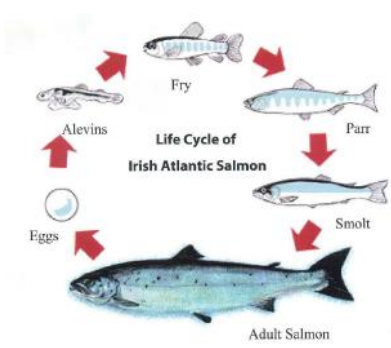

Fig. 1. Life cycle of salmon fish.
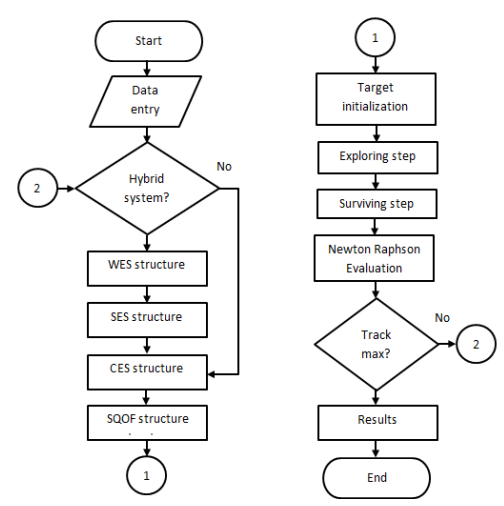

Fig. 3. Computational sequences of ASTA.

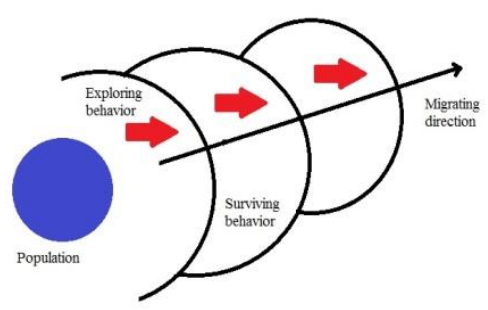

Fig. 2. Salmon migration approach.

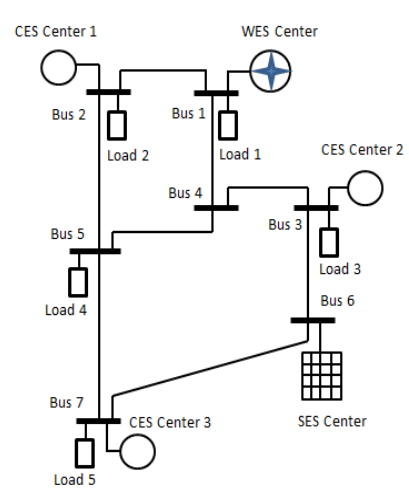

Fig. 4. Hybrid energy system model. 
Table 1. Designed hourly reactive power load.

\begin{tabular}{|c|c|c|c|c|c|c|c|}
\hline Hours & MW & Hours & MW & Hours & MW & Hours & MW \\
\hline 01.00 & 267.6 & 07.00 & 539.8 & 13.00 & 634.3 & 19.00 & 513.7 \\
\hline 02.00 & 278.8 & 08.00 & 582.4 & 14.00 & 670.5 & 20.00 & 321.1 \\
\hline 03.00 & 202.0 & 09.00 & 594.3 & 15.00 & 566.4 & 21.00 & 308.2 \\
\hline 04.00 & 283.2 & 10.00 & 627.7 & 16.00 & 313.5 & 22.00 & 301.5 \\
\hline 05.00 & 360.2 & 11.00 & 620.3 & 17.00 & 346.1 & 23.00 & 297.6 \\
\hline 06.00 & 373.9 & 12.00 & 548.6 & 18.00 & 470.4 & 24.00 & 268.6 \\
\hline
\end{tabular}

By considering Salmon's behavior, ASTA is constructed based on migrating steps as a computational intelligence referred to the exploring and surviving steps as illustrated in Figure 2. The exploring step is used to search out a mouth river for guiding a desired possibility selection. The surviving step is used to find out the returning destination to track the desired solution at all various branches. In these works, the system as given in Figure 4 is also evaluated using the Newton Raphson method for determining balanced energy performances as referred in [26], [27]. In details, Figure 3 is used to illustrate procedures for optimizing the SQF. In these works, ASTA is presented using 100 of Salmon number, 0.25 of a Surviving factor, 100 of Mouth river, 100 of Tracking round, 1 of the Migrating period, and 50 of Solution population. In particular, the system is optimized based on load demand changes for 24 hours as provided in Table I constrained by voltage fluctuations $= \pm$ $5 \%$, a compromised factor $=0.5$, the power transfer capability $=90 \%$, and the emission standard $=0.85 \mathrm{~kg} / \mathrm{MWh}$.

\section{Results and discussions}

In this section, the results are detailed in Table II for the individual commitment of the the CES while the WES and SES are considered free for the natural energy sources. This table also informs the scheduled production for 24 hours with the power fluctuation and penetration are illustrated in Figure 5 and Figure 6.

Table 2. Individual produced power.

\begin{tabular}{|c|c|c|c|c|c|c|c|c|c|c|c|}
\hline \multirow{3}{*}{ Time } & \multicolumn{5}{|c|}{ Conventional Energy Sources (MW) } & \multirow{3}{*}{ Time } & \multicolumn{5}{|c|}{ Conventional Energy Sources (MW) } \\
\hline & \multicolumn{2}{|c|}{ CES C1 } & \multicolumn{2}{|c|}{ CES C2 } & \multirow{2}{*}{$\begin{array}{c}\text { CES C3 } \\
\text { Unit } 1 \\
\text { G5 }\end{array}$} & & \multicolumn{2}{|c|}{ CES C1 } & \multicolumn{2}{|c|}{ CES C2 } & \multirow{2}{*}{$\begin{array}{c}\text { CES } \\
\text { C3 } \\
\text { Unit 1 } \\
\text { G5 }\end{array}$} \\
\hline & $\begin{array}{c}\text { Unit } 1 \\
\text { G1 }\end{array}$ & $\begin{array}{c}\text { Unit } 2 \\
\text { G2 }\end{array}$ & $\begin{array}{c}\text { Unit } 1 \\
\text { G3 }\end{array}$ & $\begin{array}{c}\text { Unit } 2 \\
\text { G4 }\end{array}$ & & & $\begin{array}{c}\text { Unit } 1 \\
\text { G1 }\end{array}$ & $\begin{array}{c}\text { Unit } 2 \\
\text { G2 }\end{array}$ & $\begin{array}{c}\text { Unit } 1 \\
\text { G3 }\end{array}$ & $\begin{array}{c}\text { Unit } 2 \\
\text { G4 }\end{array}$ & \\
\hline 01.00 & 61.48 & 21.97 & 20.54 & 24.19 & 25.81 & 13.00 & 255.04 & 90.99 & 90.00 & 84.73 & 90.96 \\
\hline 02.00 & 53.79 & & 23.77 & 27.57 & 25.32 & 14.00 & 264.04 & 25 & 97.69 & 5.63 & 96.11 \\
\hline 03.00 & 60.00 & & 36.20 & 22.42 & 27.89 & 15.00 & 235.22 & 82.35 & 95.31 & 53 & 2.18 \\
\hline 04.00 & 85.60 & & 83.04 & & 36.04 & 16.00 & 95.89 & 48.84 & 45.04 & 41.81 & 22.41 \\
\hline 05.00 & 122.89 & & 70.25 & 84.86 & 72.39 & 17.00 & 99.72 & 58.75 & 79.75 & 79 & 23.45 \\
\hline 06.00 & 129.15 & & 78.71 & 75.11 & & 18.00 & 183.30 & 74.00 & 73.14 & 57 & 63.94 \\
\hline 07.00 & 9.47 & & & & & 19.00 & 183.29 & & 83.18 & 96 & 82.73 \\
\hline 08.00 & 145.15 & & & & & 20.00 & 183.24 & & 76.73 & & 71.71 \\
\hline 09.00 & 133.49 & & & & & 21.00 & 162.31 & & 74.51 & 3 & 72.61 \\
\hline 10.00 & 216.09 & 70.05 & 70.94 & 67.64 & & 22.00 & 121.67 & 68 & 60.12 & 6 & 63.61 \\
\hline 11.00 & 2.98 & 98.13 & 96.11 & 98.62 & 31.15 & 23.00 & 58.25 & & 31.06 & 33.33 & 30.07 \\
\hline 12.00 & 250.11 & 84.25 & 93.68 & 82.73 & 84.96 & 24.00 & 49.38 & 35.15 & 23.77 & 27.89 & 26.70 \\
\hline
\end{tabular}




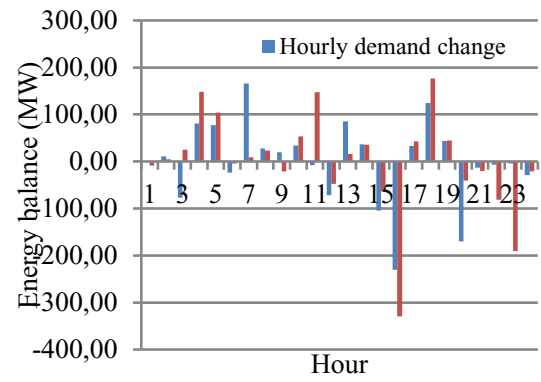

Fig. 5. Hourly energy fluctuation.

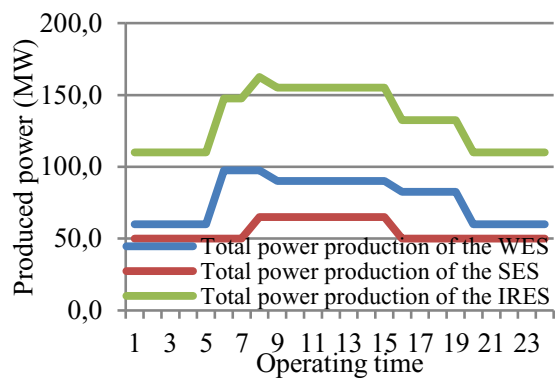

Fig. 6. IRES penetration.

Table 3. Effective operating penetration.

\begin{tabular}{|c|c|c|c|c|c|c|c|c|c|}
\hline \multirow{2}{*}{ Hour } & & \multicolumn{9}{|c|}{ Total Power Balance (MW) } & \multicolumn{3}{c|}{ Pollutant Discharge (kg) } \\
\cline { 2 - 11 } & Demand & $\begin{array}{c}\text { Effective } \\
\text { Demand }\end{array}$ & CES & SES & WES & Total & Prod. & Permit & Over \\
\hline 01.00 & 267.6 & 157.6 & 154.0 & 50.0 & 60.0 & 264.0 & 158.2 & 130.9 & 76.5 \\
\hline 02.00 & 278.8 & 168.8 & 158.8 & 50.0 & 60.0 & 268.8 & 169.4 & 135.0 & 79.9 \\
\hline 03.00 & 202.0 & 92.0 & 183.9 & 50.0 & 60.0 & 293.9 & 198.9 & 156.3 & 91.3 \\
\hline 04.00 & 283.2 & 173.2 & 332.2 & 50.0 & 60.0 & 442.2 & 537.3 & 282.3 & 306.6 \\
\hline 05.00 & 360.2 & 250.2 & 435.7 & 50.0 & 60.0 & 545.7 & 809.0 & 370.4 & 465.0 \\
\hline 06.00 & 373.9 & 226.4 & 431.5 & 50.0 & 97.5 & 579.0 & 783.7 & 366.8 & 435.6 \\
\hline 07.00 & 539.8 & 392.3 & 440.7 & 50.0 & 97.5 & 588.2 & 830.5 & 374.6 & 474.2 \\
\hline 08.00 & 582.4 & 419.9 & 463.7 & 65.0 & 97.5 & 626.2 & 897.6 & 394.1 & 498.0 \\
\hline 09.00 & 594.3 & 439.3 & 442.6 & 65.0 & 90.0 & 597.6 & 826.4 & 376.2 & 463.0 \\
\hline 10.00 & 627.7 & 472.7 & 495.9 & 65.0 & 90.0 & 650.9 & 979.6 & 421.5 & 558.2 \\
\hline 11.00 & 620.3 & 465.3 & 643.6 & 65.0 & 90.0 & 798.6 & $1,641.9$ & 547.0 & $1,094.8$ \\
\hline 12.00 & 548.6 & 393.6 & 595.7 & 65.0 & 90.0 & 750.7 & $1,413.8$ & 506.4 & 907.4 \\
\hline 13.00 & 634.3 & 479.3 & 611.7 & 65.0 & 90.0 & 766.7 & $1,484.8$ & 520.0 & 964.8 \\
\hline 14.00 & 670.5 & 515.5 & 647.7 & 65.0 & 90.0 & 802.7 & $1,669.5$ & 550.6 & $1,118.9$ \\
\hline 15.00 & 566.4 & 411.4 & 583.7 & 65.0 & 90.0 & 738.7 & $1,357.2$ & 496.1 & 861.0 \\
\hline 16.00 & 313.5 & 181.0 & 254.0 & 50.0 & 82.5 & 386.5 & 296.1 & 215.9 & 128.3 \\
\hline 17.00 & 346.1 & 213.6 & 296.5 & 50.0 & 82.5 & 429.0 & 424.0 & 252.0 & 218.2 \\
\hline 18.00 & 470.4 & 337.9 & 473.0 & 50.0 & 82.5 & 605.5 & 888.5 & 402.0 & 486.5 \\
\hline 19.00 & 513.7 & 381.2 & 517.5 & 50.0 & 82.5 & 650.0 & $1,073.1$ & 439.9 & 633.2 \\
\hline 20.00 & 321.1 & 211.1 & 476.6 & 50.0 & 60.0 & 586.6 & 895.8 & 405.1 & 490.7 \\
\hline 21.00 & 308.2 & 198.2 & 456.0 & 50.0 & 60.0 & 566.0 & 834.0 & 387.6 & 446.4 \\
\hline 22.00 & 301.5 & 191.5 & 374.7 & 50.0 & 60.0 & 484.7 & 584.6 & 318.5 & 293.9 \\
\hline 23.00 & 297.6 & 187.6 & 183.9 & 50.0 & 60.0 & 293.9 & 202.4 & 156.3 & 93.9 \\
\hline 24.00 & 268.6 & 158.6 & 162.9 & 50.0 & 60.0 & 272.9 & 179.1 & 138.5 & 83.2 \\
\hline
\end{tabular}

Table III shows the penetration and emission while hourly conditions are presented in Figure 5 and Figure 6 . The system produces 12,989 MW to meet the load of 10,290.7 MW. This power is supported by 9,816.05 MW of the CES, 1,320.00 MW of the SES, and $1,852.50$ of the WES. The emission also is produced in $19,135.40 \mathrm{~kg}$ which is allowed in $8,344.00 \mathrm{~kg}$ and overed in $11,269.50 \mathrm{~kg}$.

\section{Conclusion}

This paper presents Artificial Salmon Tracking Algorithm applied to the energy mix composition considering renewable energy sources. The obtained results show that the produced power is affected by renewable energy sources whereas conventional producers 
take place in different capacities for the commitment. From these works, the real implementation of ASTA is devoted for future works.

The authors gratefully acknowledge the support of the PNBP Research Program, Universitas Negeri Malang, Malang, Indonesia.

\section{References}

1. S. Akın, IEEE Communications Letters, 21 (2017)

2. A. Rabiee, B. Mohammadi-Ivatloo, and M. Moradi-Dalvand, IEEE Transactions on Power Systems, 29 (2014)

3. Y. Shang, S. Lu, J. Gong, R. Liu, X. Li, and Q. Fan, Journal of Hydrology, 554 (2017)

4. A. N. Afandi, I. Fadlika, and Y. Sulistyorini, 3rd Conference on Power Engineering and Renewable Energy (ICPERE), (2016)

5. P. Cuffe and A. Keane, IEEE Systems Journal, 11 (2017)

6. L. Wang, W. Liu, D. Malcolm, and Y. F. Liu, IEEE Transactions on Power Electronics, (2017)

7. M. EL-Shimy, N. Mostafa, A. N. Afandi, A. M. Sharaf, and M. A. Attia, Mathematics and Computers in Simulation, (2018)

8. L. T. Al Bahrani and J. C. Patra, Applied Soft Computing, 58 (2017)

9. A. N. Afandi, International Journal of Engineering and Technology, 8 (2016)

10. L. Labib, M. Billah, G. M. S. M. Rana, M. N. Sadat, M. G. Kibria, and M. R. Islam, Transmission Distribution IET Generation, 11 (2017)

11. A. N. Afandi et al., International Review of Electrical Engineering (IREE), 13 (2018)

12. A. N. Afandi, I. Fadlika, and Y. Sulistyorini, 2016 3rd Conference on Power Engineering and Renewable Energy (ICPERE), (2016)

13. M. Bhoye, M. H. Pandya, S. Valvi, I. N. Trivedi, P. Jangir, and S. A. Parmar, 2016 International Conference on Energy Efficient Technologies for Sustainability (ICEETS), (2016)

14. Y. Cheng, W. Xiao, W. J. Lee, and M. Yang, 41st North American Power Symposium, (2009)

15. Y. Di, M. Fei, L. Wang, and W. Wu, Energy Procedia, 61 (2014)

16. Y. Li, S. Miao, X. Luo, and J. Wang, 2016 22nd International Conference on Automation and Computing (ICAC), (2016)

17.P. Boonserm and S. Sitjongsataporn, 2017 International Electrical Engineering Congress (iEECON), (2017)

18. B. Chowdhury and G. Garai, Genomics, 109 (2017)

19. A. N. Afandi, Y. Sulistyorini, G. Fujita, N. P. Khai, and N. Tutkun, 2017 4th International Conference on Electrical Engineering, Computer Science and Informatics (EECSI), (2017)

20. D. Arengga, W. Agustin, Y. Rahmawati, S. Sendari, and A. N. Afandi, IOP Conf. Ser.: Earth Environ. Sci., 105 (2018)

21. A. N. Afandi, Wseas Transactions On Business And Economics, 14 (2017)

22. S. L. Haeseker, R. M. Peterman, Z. Su, and C. C. Wood, North American Journal of Fisheries Management, 28 
23. A. B. Kristoffersen, D. Jimenez, H. Viljugrein, R. Grøntvedt, A. Stien, and P. A. Jansen, Epidemics, 9 (2014)

24. A. B. Kristoffersen, L. Qviller, K. O. Helgesen, K. W. Vollset, H. Viljugrein, and P. A. Jansen, Epidemics, 23 (2018)

25. K. W. Vollset, B. T. Barlaup, H. Skoglund, E. S. Normann, and O. T. Skilbrei, Biology Letters, 10 (2014)

26. S. Chatterjee and S. Mandal, 2017 International Conference on Power and Embedded Drive Control (ICPEDC) (2017)

27. J.-J. Deng and H.-D. Chiang, Journal of Applied Mathematics, (2013) 